Frontiers of Supercomputing II 


\section{Published Titles in the Los Alamos Series in Basic and Applied Sciences \\ Edited by David H. Sharp and L. M. Simmons, Jr.}

1. Wildon Fickett and William C. Davis, Detonation

2. Charles L. Mader, Numerical Modeling of Detonation

3. Robert D. Cowan, The Theory of Atomic Structure and Spectra

4. Ben R. Finney and Eric M. Jones, eds., Interstellar Migration and the Human Experience

5. Wildon Fickett, Introduction to Detonation Theory

6. Grant Heiken and Kenneth Wohletz, Volcanic Ash

7. N. Metropolis, D. H. Sharp, W. J. Worlton, and K. R. Ames, eds., Frontiers of Supercomputing

8. Charles L. Mader, Numerical Modeling of Water Waves

9. S. Kass, J. Patera, R. Moody, and R. Slansky, Affine Lie Algebras, Weight Multiplicities, and Branching Rules

10. S. M. Ulam, Analogies between Analogies: The Mathematical Reports of S. M. Ulam and His Los Alamos Collaborators

11. Torlief E. O. Ericson, Vernon W. Hughes, Darragh E. Nagel, and John C. Allred, The Meson Factories

12. Karyn R. Ames and Alan Brenner, eds., Frontiers of Supercomputing II: A National Reassessment 


\title{
Frontiers of Supercomputing II
}

A National Reassessment

\author{
Edited by \\ Karyn R. Ames \\ and \\ Alan Brenner
}

UNIVERSITY OF CALIFORNIA PRESS

Berkeley Los Angeles London 
University of California Press

Berkeley and Los Angeles, California

University of California Press

London, England

Copyright (C) 1994 by The Regents of the University of California

\section{Library of Congress Cataloging-in-Publication Data}

Frontiers of supercomputing II: a national reassessment / edited by Karyn R. Ames and Alan Brenner.

p. cm.-(Los Alamos series in basic and applied sciences;

Papers from the 2nd Frontiers of Supercomputing Conference held at Los Alamos National Laboratory, 8/20-24/90.

Includes bibliographical references.

ISBN 0-520-08401-2 (acid-free paper)

1. Supercomputers-Congresses. I. Ames, Karyn R. II. Brenner,

Alan. III. Frontiers of Supercomputing Conference (2nd: 1990: Los

Alamos National Laboratory). IV. Title: Frontiers of supercomputing two. V. Title: Frontiers of supercomputing 2. VI. Series.

QA76.88.F76 1994

338.4'700411'0973-dc20

Printed in the United States of America

123456789

The paper used in this publication meets the minimum requirements of American National Standard for Information Sciences-Permanence of Paper for Printed Library Materials, ANSI Z39.48-1984 @ 